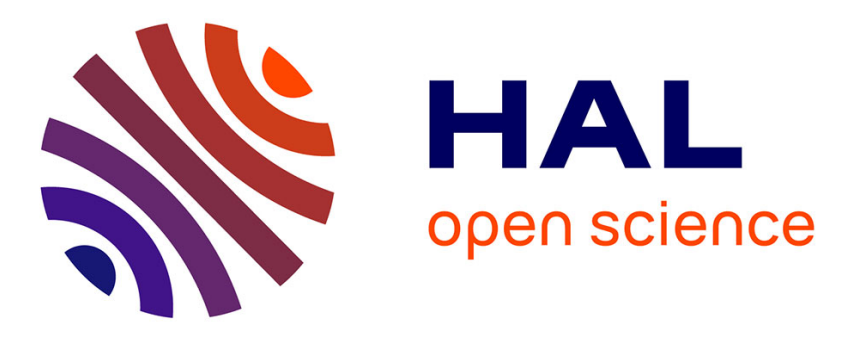

\title{
Aerosol Plume Characterization From Multitemporal Hyperspectral Analysis
}

\author{
Pierre-Yves Foucher, Philippe Déliot, Laurent Poutier, Olivier Duclaux, \\ Valentin Raffort, Yelva Roustan, Brice Temime-Roussel, Amandine Durand, \\ Henri Wortham
}

\section{To cite this version:}

Pierre-Yves Foucher, Philippe Déliot, Laurent Poutier, Olivier Duclaux, Valentin Raffort, et al.. Aerosol Plume Characterization From Multitemporal Hyperspectral Analysis. IEEE Journal of Selected Topics in Applied Earth Observations and Remote Sensing, 2019, 12 (7), pp.2429-2438. 10.1109/JSTARS.2019.2905052 . hal-02296714

\section{HAL Id: hal-02296714 https://hal.science/hal-02296714}

Submitted on 25 Sep 2019

HAL is a multi-disciplinary open access archive for the deposit and dissemination of scientific research documents, whether they are published or not. The documents may come from teaching and research institutions in France or abroad, or from public or private research centers.
L'archive ouverte pluridisciplinaire HAL, est destinée au dépôt et à la diffusion de documents scientifiques de niveau recherche, publiés ou non, émanant des établissements d'enseignement et de recherche français ou étrangers, des laboratoires publics ou privés. 


\title{
AEROSOL PLUME CHARACTERISATION FROM MULTI-TEMPORAL HYPERSPECTRAL ANALYSIS
}

\author{
Pierre Yves Foucher ${ }^{\mathrm{a}}$, Philippe Déliot ${ }^{\mathrm{a}}$, Laurent Poutier $^{\mathrm{a}}$ Olivier Duclaux $^{\mathrm{b}}$, Valentin Raffort ${ }^{\mathrm{c}}$, \\ Yelva Roustanc, Brice Temime-roussel $^{\mathrm{d}}$, Amandine Durand ${ }^{\mathrm{d}}$, Henri Wortham ${ }^{\mathrm{d}}$.
}

${ }^{a}$ ONERA, The French Aerospace Lab, Toulouse Center, 2 Av. Edouard Belin, 31055 Toulouse, France ;

b'Laboratoire Qualité de l'Air, TOTAL, 69360 Solaize, France ;

${ }^{\circ}$ CEREA, Ecole des Ponts ParisTech/EDF R\&D, Université Paris-Est, 77455 Champs-sur-Marne, France.

'Aix Marseille Univ, CNRS, LCE, UMR 7376, 13331 Marseille, France.

\begin{abstract}
In this paper we focus on airborne hyperspectral imaging methodology to characterize PM (Particulate Matter) near industrial emission sources. Two short-term intensive campaigns were carried out in the vicinity of a refinery in the South of France, in September 2015 and February 2016. Different protocols of in-situ PM measurements were performed, at stack measurements (flow rate and offline chemical analysis) and on-line measurement at the refinery border (size distribution, concentration and chemistry of aerosols). A multi temporal methodology to retrieve aerosol type, to map the aerosol concentration and to quantify mass flow rate from airborne hyperspectral data is described in this paper. This method applied to the refinery detected plume from the main stack yields a black carbon to sulfate ratio of 10/90 in mass inside the plume, with an average size distribution smaller than $100 \mathrm{~nm}$. These results are in a good agreement with on-line analysis of aerosols at refinery border. The resulting quantitative map with a metric spatial resolution leads to a flow rate estimated of about $1 \mathrm{~g} / \mathrm{s}$ and is in a good agreement with in-situ stack measurements and modelling.
\end{abstract}

Index Terms- Hyperspectral, aerosols, multitemporal, airborne, model

\section{INTRODUCTION}

It is well known that particles suspended in the atmosphere have a major role in the Earth's global radiation budget, as reported by the IPCC (Intergovernmental Panel on Climate Change) and are involved in several pollution events. Their study is essential for a better comprehension of climate change and in term of public health. In particular, anthropogenic aerosols contribute to $10 \%$ of the total mass of pollutants (gases and aerosols) rejected into the atmosphere and their corresponding cost terms of public health is estimated to be about 200 billion $€$ per year in 2000 for the 25 countries of Europe [4].

For these reasons, remote sensing tools are widely used to study aerosols and to provide a quantitative characterization of aerosols distribution at a global or regional scale $[13][11][9][10][3]$. Most of the existing sensors enabling to characterize aerosols from space have spatial resolutions range from $100 \mathrm{~m}$ to $1 \mathrm{~km}$ but their associated products are not suited to study industrial aerosols close to their emission points. A finer spatial resolution can be obtained by using airborne sensors as their metric to decametric resolutions are adapted to the spatial extents of industrial plumes, or for urban area studies. Hyperspectral sensors thus have an interesting potential for the characterization of industrial aerosols. The hundreds of spectral bands from 0.4 to $2.5 \mu \mathrm{m}$ can provide spectral information related to the PM2.5 size and composition (particles with a diameter less than $2.5 \mu \mathrm{m}$ ) mostly associated to pollutant of anthropogenic origins. Hyperspectral methods have been developed in these way in order to study aerosols [1][2][5][6][16] but there is still a lack of sensitivity for thin anthropogenic plumes, mainly due to the high heterogeneity of the background in urban or industrial areas. However multi-temporal analysis is a key benefit from spatial data to extract background variability from atmospheric aerosols radiative impacts [8]. In this way, this paper plans to use both multi-temporal benefit and high spectral and spatial resolution from hyperspectral data to detect and characterize thin aerosols plumes near anthropogenic sources. The main point presented here is the use of both spatial and temporal analysis to separate soil and aerosols spectral signatures using dedicated multi-temporal airborne hyperspectral imaging data.

In the context of the TEMMAS (TEledetection, Measure, Modeling of Atmospheric pollutants on industrial Sites) 
project, supported by the French environment agency (ADEME), intensive measurements of gaseous and particulate pollutants were conducted in the vicinity of a TOTAL's refinery in September 2015 and February 2016 [7]. The aim of these campaigns was to study the refinery Particulate Matter (PM) microphysical signatures and their evolution with distance to the source in the first kilometers. Considering the large sources of uncertainties in air quality models, both in the used input data (meteorology, emissions...) and in the model formulations, high resolution measurements, associated with a complete characterization of PM size and composition, is a promising approach to better understand those uncertainties, and to improve the representation of PM in the vicinity of industrial sites.

In this paper we focus on results from TEMMAS airborne hyperspectral imaging data to characterize PM composition and size near the plume emission source (first hundred meters). Hyperspectral results are then compared to in-situ measurements (in stack measurements and on-line analysis at refinery border) and to plumes simulated with the Polyphemus Plume-in-Grid model (PinG) [12][17], applied at the regional scale, and by the Lagrangian model SLAM (Safety Lagrangian Atmospheric Model [19]), applied at the refinery scale.

\section{AIRBORNE HYPERSPECTRAL MULTI- TEMPORAL DATA}

The site of TEMMAS experiments was a TOTAL's refinery in South of France where several flights have been carried out from the $7^{\text {th }}$ and $8^{\text {th }}$ of September 2015. A picture of the refinery is shown in Figure 1, the two main aerosol sources correspond to the boiler $\mathrm{CH} 11$ and flare T2. Figure 2 shows the entire area covered by the different flights. The refinery appears as the bright part near the Berre Pound coast in the northern part of the mosaic

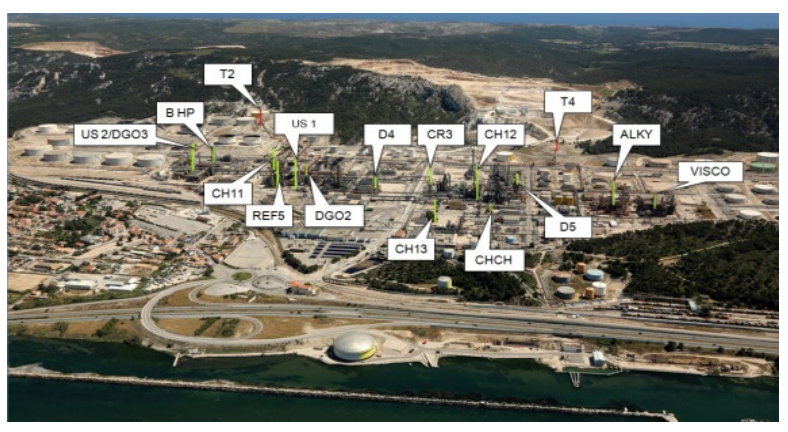

Figure 1 : Locations of different exhaust stack in the refinery. Main aerosols exhaust stack are the boiler CH11 and flare T2.
The onboard optronic sensors are composed of two HySpex VNIR1600 and SWIR320m-e hyperspectral cameras built by NEO (Norsk Elektro Optikk). VNIR1600 covers the full range of 410 to $996 \mathrm{~nm}$ with 160 spectral bands with a spectral sampling of $3.6 \mathrm{~nm}$ while the SWIR320m-e based on a MCT FPA (Focal Plane Array) covers the extended domain of 970 to $2500 \mathrm{~nm}$ with a spectral sampling of $6 \mathrm{~nm}$. They offer a total of 410 different spectral bands providing a high spectral resolution of the scene. The cameras acquire the data synchronously on both spectral domains but considering the instantaneous field of view (iFOV) along track and across track of the VNIR, $0.37 \times 0.185 \mathrm{mrad}$, and the SWIR, $0.75 \times 0.75 \mathrm{mrad}$, pixels of the SWIR camera are twice larger along track and four times larger across track than the VNIR ones. With 1600 pixels for the VNIR camera and 320 pixels for the SWIR one, the resulting field of view, across track, is about $17^{\circ}$ and $14^{\circ}$ respectively for the VNIR and SWIR sensor. The main parameters of optical sensors operated during the TEMMAS campaign are resumed in the table 1.

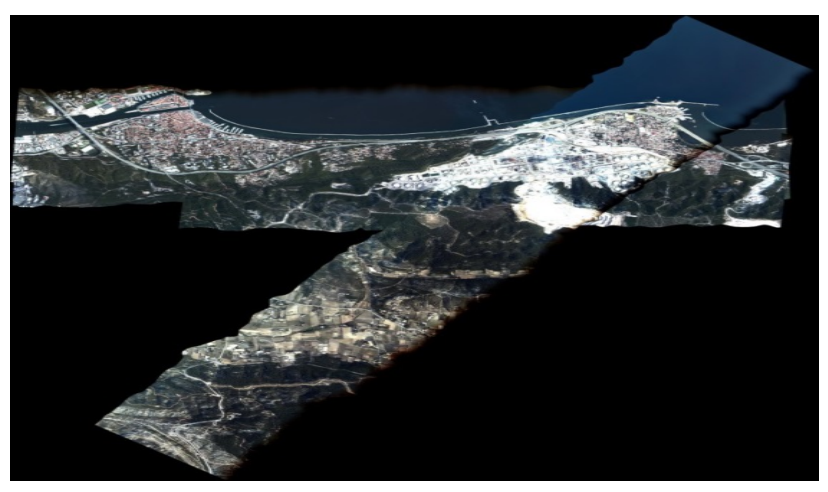

Figure 2: Mosaic of hyperspectral acquisitions above the refinery area using Hyspex hyperspectral instrument. The refinery appears as the bright part near the coastal area (Berre Pound).

These cameras were installed inside an ATR42 belonging to the SAFIRE fleet (French facility for airborne research). More than 10 flight lines have been carried out from 8 am to $3 \mathrm{pm}$ (local time) for each day. Thanks to inertial measurements we were able to produce ortho-rectified images using a process based on PARGE software [18]. Atmospheric correction with the COCHISE algorithm [15] was applied to estimate atmospheric and solar radiative contribution to hyperspectral data and then provide reflectance images. COCHISE is the reciprocal code of COMANCHE [15], this algorithm computes the incoming spectral radiance at the sensor level, for an instrument operating in the VIS - LWIR spectral range and observing a target over a background. COMANCHE uses an analytical formulation of the upwelling radiance at the sensor level in 
which the atmospheric parameters are independent of the ground parameters. The formulation includes the environmental effects due to scattering (trapping effects and diffuse transmission). The atmospheric parameters are extracted from MODTRAN computations and the environment functions are obtained using two Monte-Carlo codes. COCHISE retrieves the $2 \mathrm{D}$ ground spectral reflectance from a calibrated hyperspectral image.
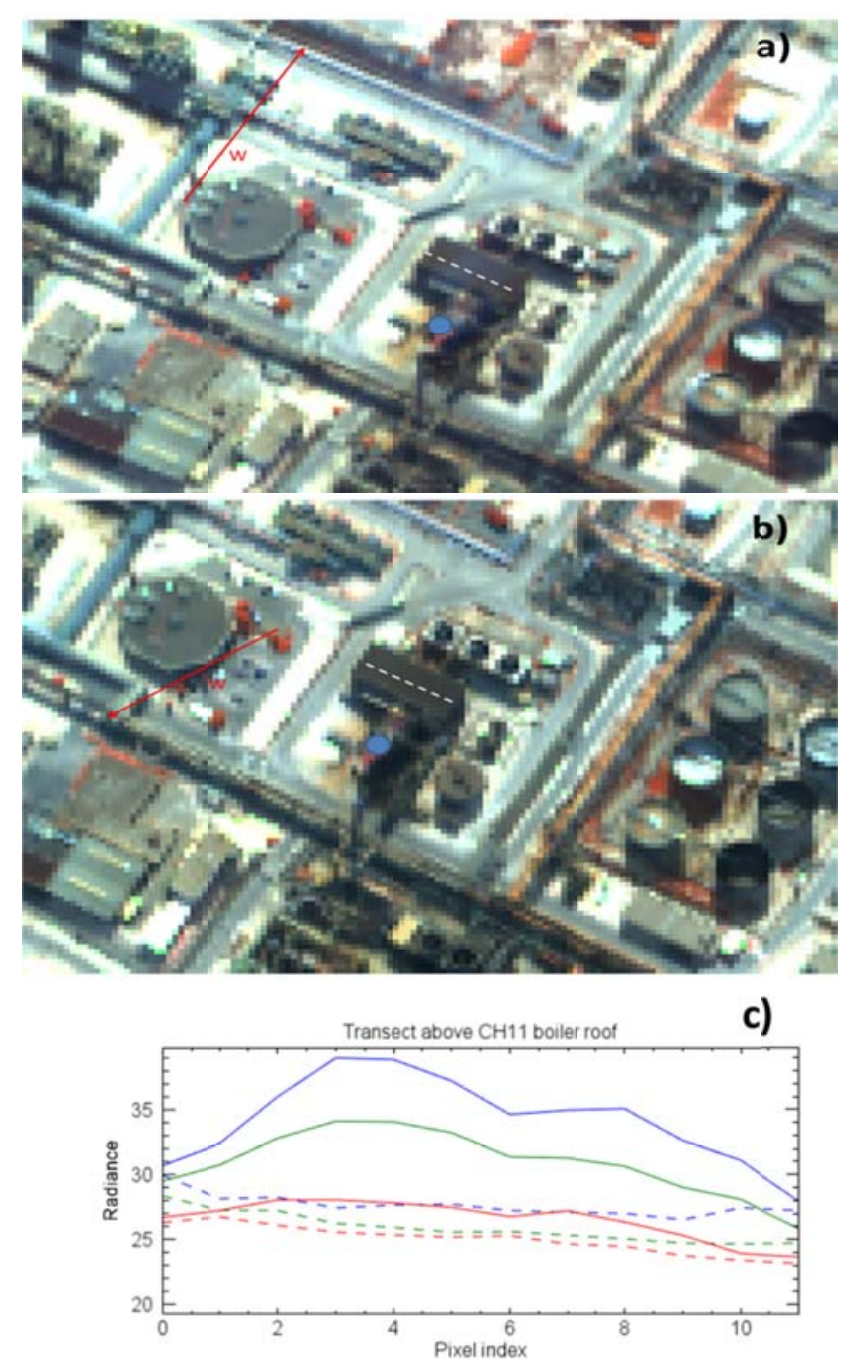

Figure 3 : Example of the main exhaust stack (Boiler CH11 corresponding to the blue points) plume acquisition in "real color" (RGB : 750, 550 and $450 \mathrm{~nm}$ ) from two different flights the same day, a) :before (top image) and b) after (bottom image) the wind direction change from $\mathrm{S}-\mathrm{O}$ to $\mathrm{N}-\mathrm{E}$ (red arrows). In the first image the plume might only be seen on the roof of the boiler in the white dashed transect area. Figure c) corresponds to radiance values along the transect for each channel (red : 750nm, blue : $550 \mathrm{~nm}$, green :450nm) in the case of figure a) and figure b) (dashed lines). The plume is "seen" in the green and the blue channel over the roof

The main plume of the refinery is optically very thin. Figure 3 shows nearly real color (RGB : 750, 550 and $450 \mathrm{~nm}$ ) image of the CH11 boiler (blue point). In the first case when wind comes from the North (Figure 3a) the plume is slightly "seen" when passing above the dark roof (corresponding to the white dashed transect in the figures). When wind comes from the South (bottom figure), the plume completely disappears in the image due to soil heterogeneity and quite high reflectance. Figure $3 \mathrm{c}$ shows that the plume radiance impact is the most important at $450 \mathrm{~nm}$ (maximum relative increases of $40 \%$ ) and weak at $750 \mathrm{~nm}$ (maximum relative increases of $10 \%$ ). But it is true that the plume remains still very difficult to be detected. However we have seen that plume impact is spectrally dependent. The aim of the multi-temporal analysis is to extract reflectance signatures from the plume "free" image. In this case for example, the bottom image $3 b$ will give us a reference for the roof. During this campaign we use the temporal variations of the plume direction with in a day corresponding to different wind directions. Indeed, in the coastal Berre Pound area during summer typical winds are from the Sea (South) but in the early morning (around 8am) a continental wind appears (from the North) still 12am or $1 \mathrm{pm}$. This situation occurred from the $8^{\text {th }}$ to the $10^{\text {th }}$ of September. For these reasons our analysis will focus on the temporal changes that occurred from $9 \mathrm{am}$ to $1 \mathrm{pm}$ the $8^{\text {th }}$ of September. 
Table 1: Airborne Hyperspectral data main characteristics

\begin{tabular}{|l|l|l|}
\hline Characteristics & HySpex VNIR & HySpex SWIR \\
\hline Type of acquisition & Push-broom & Push-broom \\
\hline Number of pixels & 1600 & 320 \\
\hline Field of view & $17^{\circ}$ & $14^{\circ}$ \\
\hline Spectral Interval & $0,4-1 \mu \mathrm{m}$ & $1-2,5 \mu \mathrm{m}$ \\
\hline $\begin{array}{l}\text { Number of spectral } \\
\text { bands }\end{array}$ & 160 & 256 \\
\hline $\begin{array}{l}\text { Spectral sampling } \\
\text { step on the ground (@ } \\
2667 \mathrm{~m}) \text { perpendicular } \\
\text { to the direction of } \\
\text { flight }\end{array}$ & $3,50 \mathrm{~m}$ & $6 \mathrm{~nm}$ \\
\hline $\begin{array}{l}\text { step on the ground (@ } \\
2667 \mathrm{~m}) \text { parallel to the } \\
\text { direction of flight }\end{array}$ & $1,00 \mathrm{~m}$ & $2,00 \mathrm{~m}$ \\
\hline $\begin{array}{l}\text { Swath at 2667m } \\
\text { (height / ground) }\end{array}$ & $800 \mathrm{~m}$ & $2,00 \mathrm{~m}$ \\
\hline
\end{tabular}

In this way, each line of flight corresponding to different wind direction has been proceed using GEFOLKI tool [14] to ensure subpixel spatial co-registration between the orthorectified images. Figure 4 shows an example of result above the refinery. In this figure each color corresponds to a specific line of flight at $450 \mathrm{~nm}$ wave length. The central part of the image (intersection of line of flights) is mostly well registered (black and white image). However specific points or area near edge of tanks in particular are seen in a specific color (and no more in black and white). It could means that the registration error is important for at least one image. However these artefacts are mostly due to non lambertian effects (change of solar position introduces a natural temporal shift of the nadir reflectance for metallic surfaces) and moreover to shadows extensions changes from a flight to another. These specifics pixels will be rejected in the retrieval method.

Another key point is the need to correct cirrus or thin clouds effects. Temporal change of clouds or cirrus coverage creates intense temporal change unlinked to aerosol plumes. These effects are corrected assuming that cirrus or thin cloud transmissions are spectrally flat in the considered solar domain. In this way, Clouds or cirrus transmissions can be estimated at $1 \mu \mathrm{m}$ spectral wavelength (where aerosols signature can be neglected). In a second step, clouds or cirrus estimated transmission are applied to all
VNIR spectral range. Figure 5a shows clouds temporal change impact on the differential image for an entire line of flight at $450 \mathrm{~nm}$. The temporal change of clouds or cirrus has an impact of 0.1 in reflectance magnitude. Figure $5 \mathrm{~b}$ is the same as Figure 5a but focused on the refinery area using a new scale range [-0.05:0.05]. Figure $5 \mathrm{c}$ shows the same area using the same scale after cloud and cirrus correction. The standard deviation of clouds temporal changes effects on the reflectance is around 0.05 which corresponds to the maximum change of reflectance seen in the aerosol plume. After clouds correction industrial main exhaust stack are enhanced (the boiler $\mathrm{CH} 11$ and the flare T2) and the standard deviation of the differential image in reflectance is around 0.01 (excluding high values from shadows or non lambertian materials).

At this stage, after all corrections, we can provide differential product in term of reflectance or radiance above the industrial site and particularly around the boiler $\mathrm{CH} 11$ for the time period of this study: between 9 am to $1 \mathrm{pm}$ (local time) the $8^{\text {th }}$ of September. Figure 6 shows the reference reflectance image (6a) and the temporal reflectance differential image (6b) at $450 \mathrm{~nm}$ above the main source of the refinery corresponding to the boiler $\mathrm{CH} 11$. The measured plume impact on the differential is between -0.05 (plume has disappears) and +0.05 (plume appears), the standard deviation of the differential measure is around 0.01. Particulars points at borders (in particular for tanks) corresponding to very high differential value (larger than 0.1 ) are rejected and arbitrary put to null value. Aerosols plume nearly invisible for the single acquisition is enhanced thanks to the temporal differential method. The wind change between the two images from S-O to N-E makes a positive differential (brighter area) in the Northern area of the boiler linked to the apparition of the aerosols plume and negative in the southern part (plume has disappeared). Figure 7 shows similar results when looking at the flare $\mathrm{T} 2$. 


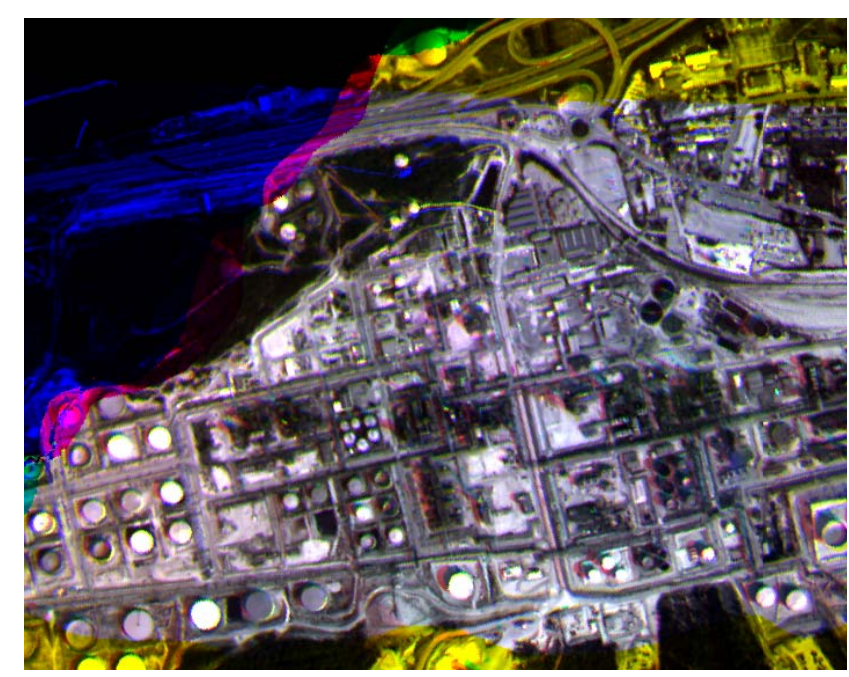

Figure 4 : Registration of 3 different lines of flight acquired during the 8th of September at different time. Registration of orthorectified images is processed using GEfolki tool. Each color (red, green and blue) correspond to the channel at $450 \mathrm{~nm}$ of each line of flight.

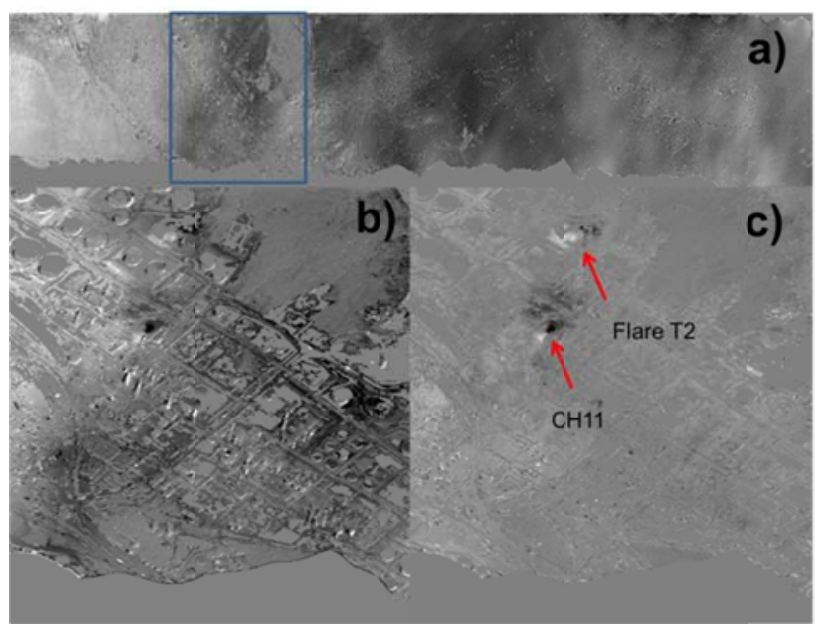

Figure 5 Top (a): Example of temporal differential at $450 \mathrm{~nm}$ for line of flight after ortho-rectification and registration (variation range scale [-0.1:0.1]). Bottom left(b) : Zoom of the top blue square image (variation range scale [-0.05:0.05]). Bottom right (c): same as left but corrected from cirrus effects: boiler CH11 plume corresponds is enhanced from the background (variation range scale [-0.05:0.05]).

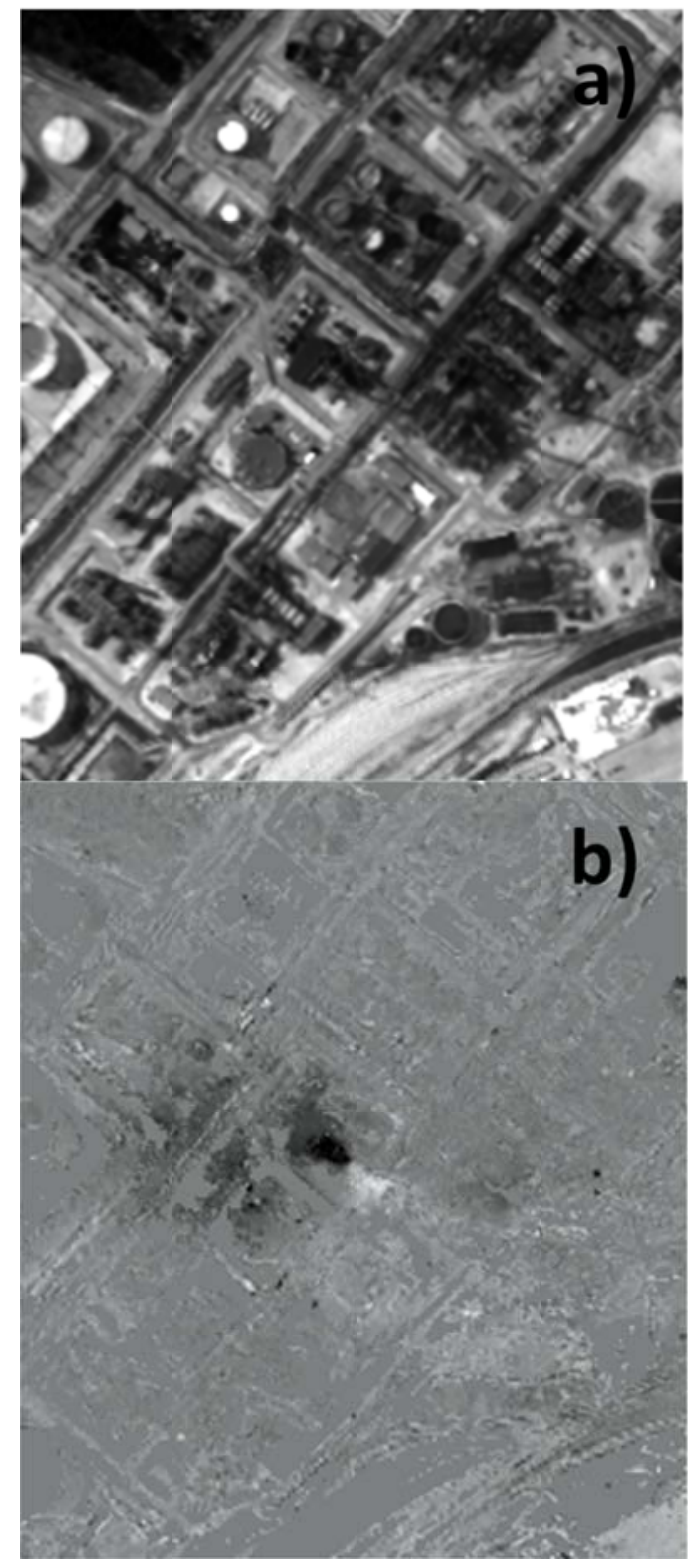

Figure 6 : Top (a): Extract of a single reflectance image at $440 \mathrm{~nm}$ above the Boiler CH11 at 440nm (scale range [0:0.3]). Bottom (b): Same extract for the same spectral channel but in differential (scale range [0.05:0.05]).

From Figure 6b) we can extract differential signatures in term of reflectance for a pixel inside the $\mathrm{CH} 11$ boiler plume. We show an example in figure 8 for a pixel in the center of the plume (not the maxima). The maximum relative difference for this pixel is around $35 \%$ below $500 \mathrm{~nm}$ and is null after $850 \mathrm{~nm}$. The mean reflectance value for this pixel is 0.15 . This first result is in coherence with the single image analysis (plume impact at $750 \mathrm{~nm}$ on the roof was very small in comparison with shorter wavelength). It 
suggests that plume is mostly composed of fine mode (size less than $0.5 \mu \mathrm{m})$ scattering aerosols. In the next part we explain how this differential signature can be related to aerosol properties (size and composition) and its corresponding concentration pixel by pixel.

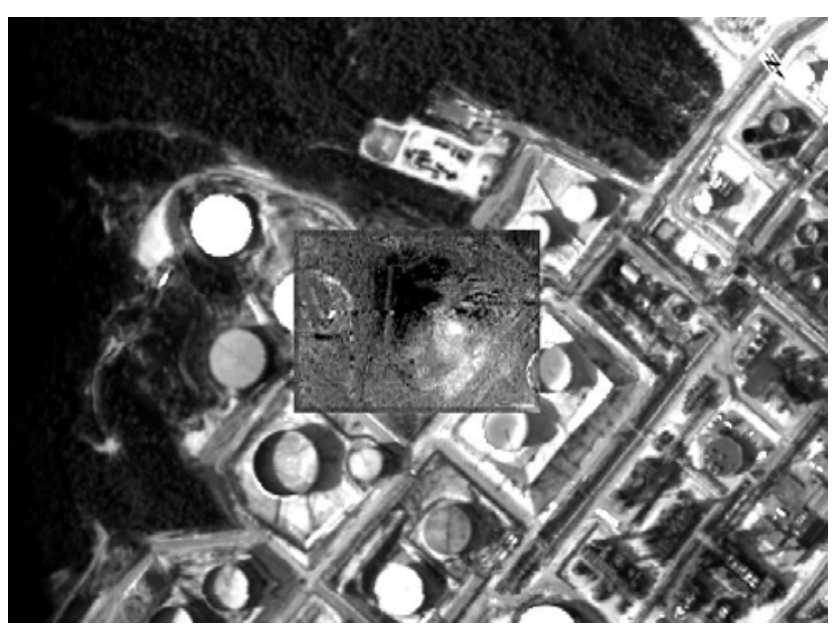

Figure 7: Same as Figure 6 for the Flare T2. The differential image is surimposed in the single image.

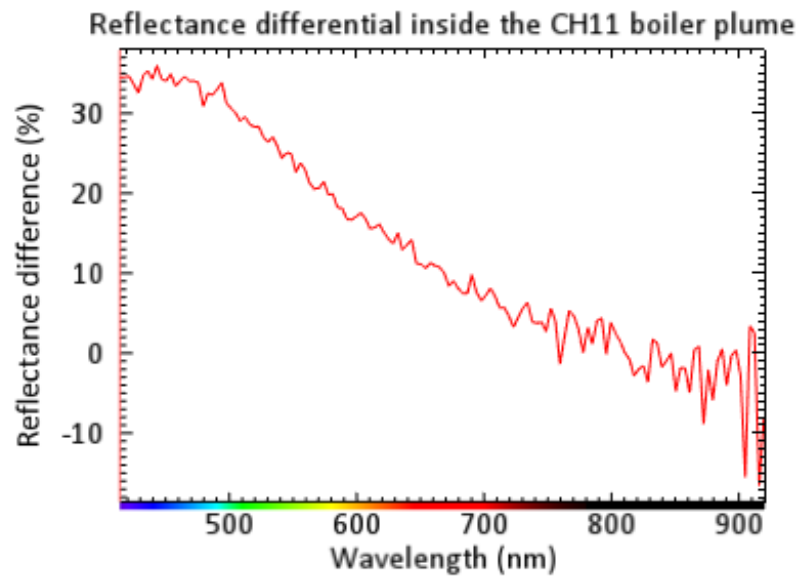

Figure 8: Temporal reflectance relative difference (\%) in the boiler CH11 plume in the VNIR spectral domain.

\section{AEROSOL RETRIEVAL HYPERSPECTRAL DATA}

Assuming a homogeneous, flat and Lambertien ground, the radiance acquired by an hyperspectral sensor $L^{\text {sensor }}(\lambda)$ is given in the reflective domain by:

$$
L^{\text {sensor }}(\lambda)=L^{\text {atm }}(\lambda)+\frac{E^{\text {surf }}(\lambda) \cdot T^{\text {atm }}(\lambda) \cdot \rho_{\text {soil }}(\lambda)}{\pi \cdot\left(1-\rho_{\text {soil }}(\lambda) \cdot s^{\text {atm }}(\lambda)\right)},
$$

where $\lambda$ stands for the wavelength, $L^{\text {atm }}(\lambda)$ is the upwelling atmospheric radiance between the surface and the sensor, $\mathrm{E}^{\text {surf }}(\lambda)$ is the total down welling irradiance at the surface, $\mathrm{T}^{\mathrm{atm}}(\lambda)$ is the total upward transmittance of the atmosphere, $\rho_{\text {soil }}(\lambda)$ is the ground reflectance and $S^{\text {atm }}(\lambda)$ is the spherical albedo of the atmosphere. All these terms are estimated from the COMANCHE and COCHISE algorithms using MODTRAN computations.

And a differential model can be expressed as follows:

$\Delta L_{\text {plume }}^{\text {sensor }}(\lambda)=L_{\text {plume }}^{\text {sensor }}(\lambda)-L_{\text {ref }}^{\text {sensor }}(\lambda)$

$\Delta L_{\text {plume }}^{\text {sensor }}(\lambda)=\Delta L_{\text {aero }}^{\text {atm }}(\lambda)+\frac{\rho_{\text {soil }}(\lambda) \Delta L_{\text {aero }}^{\text {surf }}(\lambda)}{\pi \cdot\left(1-\rho_{\text {soil }}(\lambda) \cdot \operatorname{s}^{\text {atm }}(\lambda)\right)}$

where $\Delta L_{\text {aero }}^{\text {atm }}(\lambda)$ is the atmospheric radiance variation due to aerosols and $\Delta L_{\text {aero }}^{\text {surf }}(\lambda)$ is the variation of the product of the down welling radiance and the upward atmospheric transmission. These two terms do not depend on the soil reflectance and are related to aerosol characteristics (size distribution, chemical composition and concentration). We then assume a local linearity in this model between Radiance differential signature and aerosol optical thickness (AOT) [16]:

$\Delta L_{\text {plume }}^{\text {sensor }}\left(\lambda, \tau^{550}\right)=\frac{\tau^{550}}{\tau_{\text {ref }}^{550}} \cdot \Delta L_{\text {plume }}^{\text {sensor }}\left(\lambda, \tau_{\text {ref }}^{550}\right)$

where $\tau^{550}$ is the AOT at $550 \mathrm{~nm}$ which is linked using the Mie theory to the number of aerosols per volume unit inside the plume. In the case of a plume containing $\mathrm{N}$ different types of aerosols we then assume that:

$$
\begin{aligned}
& \Delta \mathrm{L}_{\text {plume }}^{\text {sensor }}\left(\lambda, \tau^{550}\right)=\sum_{\mathrm{i}=0}^{\mathrm{N}} \mathrm{q}^{\mathrm{i}} \cdot \Delta \mathrm{L}_{\mathrm{i}}^{\text {sensor }}\left(\lambda, \tau_{\text {ref }}^{550}\right) \\
& q^{i}=\frac{\tau_{i}^{550}}{\tau_{\text {ref }}^{550}}
\end{aligned}
$$

Where $\Delta L_{i}^{\text {sensor }}\left(\lambda, \tau_{\text {ref }}^{550}\right)$ is the normalized differential radiance due the aerosol $i$ and $\tau_{i}^{550}$ is the AOT at 550nm due to the aerosol $i$. Using the Mie theory aerosol optical properties (spectral extinction $k_{\text {ext }}$, scattering coefficients $k_{\text {scat }}$ and phase function $P$ ) are estimated as a function of refractive index, size distribution. 


\section{Aerosol retrieval from multi-temporal Hyperspectral analysis}

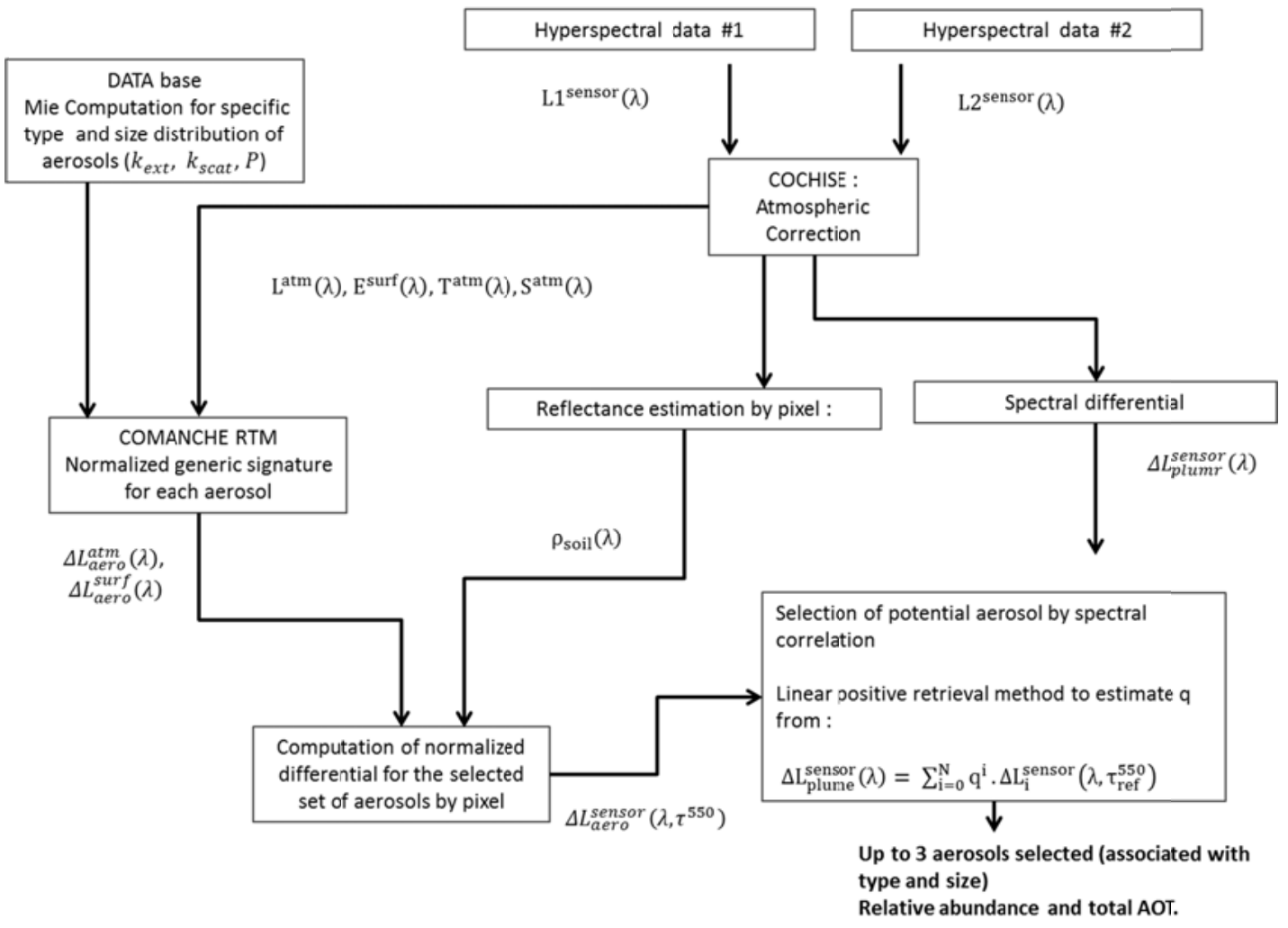

Figure 9 : Aerosol retrieval algorithm flow chart

Computations of "on" and "off" scenarios are carried out using COMANCHE algorithm to estimate $\Delta L_{\text {plume }}^{\text {atm }}$ and

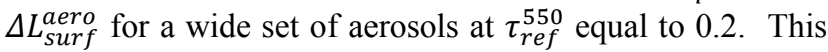
set of aerosols corresponds to organic, sulfate, black carbon (soot) and brown carbon types, for different size distribution (from $50 \mathrm{~nm}$ to $1 \mu \mathrm{m}$ ). The impact of an aerosol plume on the radiance $\Delta L_{\text {plume }}^{\text {sensor }}$ is estimated for each pixel using reflectance (firstly estimated from COCHISE algorithm) and aerosols properties. One can notice that the reflectance variation due to aerosol plume can be estimated, when $\rho_{\text {soil }}(\lambda) \cdot S^{\operatorname{atm}}(\lambda) \ll 1$, as :

$$
\Delta \rho_{\text {plume }}=\frac{\pi \Delta L_{\text {plume }}^{\text {sensor }}}{\mathrm{E}^{\text {surf }}(\lambda) \cdot \mathrm{T}^{\mathrm{atm}}(\lambda)}
$$

The differential term (in radiance or in reflectance) is computed for each pixel depending on the reflectance value. In the next part we use only radiance differential form as $\rho_{\text {soil }}(\lambda) \cdot S^{\text {atm }}(\lambda)$ term can not be neglected due to quite high level of reflectance in this image (most of reflectance are higher than 0.1). For each pixel, we then estimate the spectral correlation between the measured differential signature and each spectra simulated for each type of aerosols (and their combinations). From this point the most probable types of aerosols (type, size distribution) in the plume are selected.

The total AOT and relative contribution of each type of aerosols are estimated from the measured signatures pixel by pixel using a positive linear retrieval algorithm to retrieve the scalar $q^{i}$ described in Equation 6. Figure 9 summarizes the flow chart of the retrieval algorithm.

To illustrate the global retrieval scheme, figure 10 shows an example of a single measured differential radiance spectrum inside the plume, and the optimal spectral for this pixel. Different cases are considered in this example: (i) only Sulfate fine mode selected (green), (ii) only brown Carbon fine mode selected (blue), (iii), coupling sulfate fine mode and soot (black carbon) mode (purple). The best fit correspond to a mixing between sulfate $(90 \%)$ and black carbon (10\%) for the boiler $\mathrm{CH} 11$ plume and a total AOT of 0.3 for this pixel. The choice of aerosols is a key point, if a wrong choice is done the method will still retrieve AOT value but associated to a bad aerosol mixture.

For all the plumes form the $\mathrm{CH} 11$ boiler, two fine mode of aerosols (from $50 \mathrm{~nm}$ to $100 \mathrm{~nm}$ ), one for sulfate type and 
one for black carbon type have been selected by the method with a ratio of Sulfate of $90 \%(+/-5 \%)$. This result is very consistent with in situ measurements from the TEMMAS project [7] summarized in part 4.1.

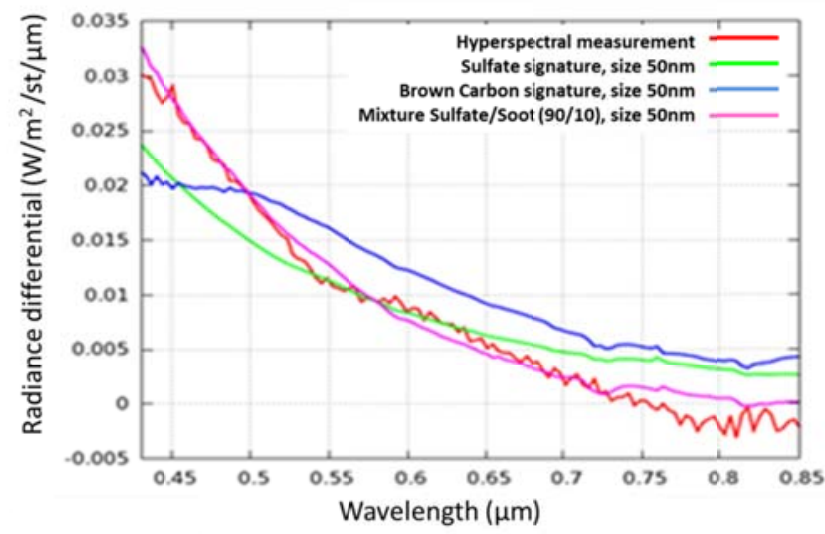

Figure 10 : Differential radiance measured (red), estimated differential for the 50nm size mode sulfate aerosol (green), for the $50 \mathrm{~nm}$ size mode of brown carbon aerosols, and the best fit in purple : $90 \%$ of $50 \mathrm{~nm}$ size mode sulfate and $10 \%$ of $50 \mathrm{~nm}$ size mode Black carbon.

\section{QUANTITATIVE ANALYSIS}

\subsection{In Situ measurements}

In situ online measurements were performed by the Massalya Platform as described in the table 2. A detailed description of the platform can be found elsewhere [20].

Table 2:Massalya Platform online instruments

\begin{tabular}{|c|c|}
\hline Instrument & Measured Parameter \\
\hline $\begin{array}{l}\text { Aerosol mass } \\
\text { spectrometer } \\
\text { (AMS) }\end{array}$ & $\begin{array}{c}\text { Chemical composition (Sulfate, nitrate, ammonium, } \\
\text { organic matter (particles of diameter lower than } 450 \\
\mathrm{~nm} \text { ) }\end{array}$ \\
\hline $\begin{array}{l}\text { Scanning Mobility } \\
\text { Particle Sizer } \\
\text { (SMPS) }\end{array}$ & $\begin{array}{l}\text { Number of particles of diameters between } 15 \text { to } 650 \\
\mathrm{~nm}\end{array}$ \\
\hline $\begin{array}{l}\text { Optical Particle } \\
\text { Counter (OPC) }\end{array}$ & $\begin{array}{l}\text { Number of particles of diameters between } 0.265 \text { to } \\
\qquad 34 \mu \mathrm{m}\end{array}$ \\
\hline $\begin{array}{l}\text { Multi-Angle } \\
\text { Absorption } \\
\text { Photometer } \\
\text { (MAAP) }\end{array}$ & $\begin{array}{l}\text { Black carbon (particles of diameter lower than } \\
4450 \mathrm{~nm} \text { ) }\end{array}$ \\
\hline
\end{tabular}

The Massalya Platform was located in the southern part of the refinery $1 \mathrm{~km}$ away from the source. The time series of PM1 and PM2.5 mass concentrations, as well as submicrometer size distributions and chemical compositions are shown in Figure 10. Figure 10 shows that particles emitted by the refinery are mainly composed of sulfate and black carbon with a mean percentage ratio of 90/10. The refinery particles size distribution centers around $50 \mathrm{~nm}$ (range $15-150 \mathrm{~nm}$ ). These results are very consistent with hyperspectral analysis discussed in part 3.

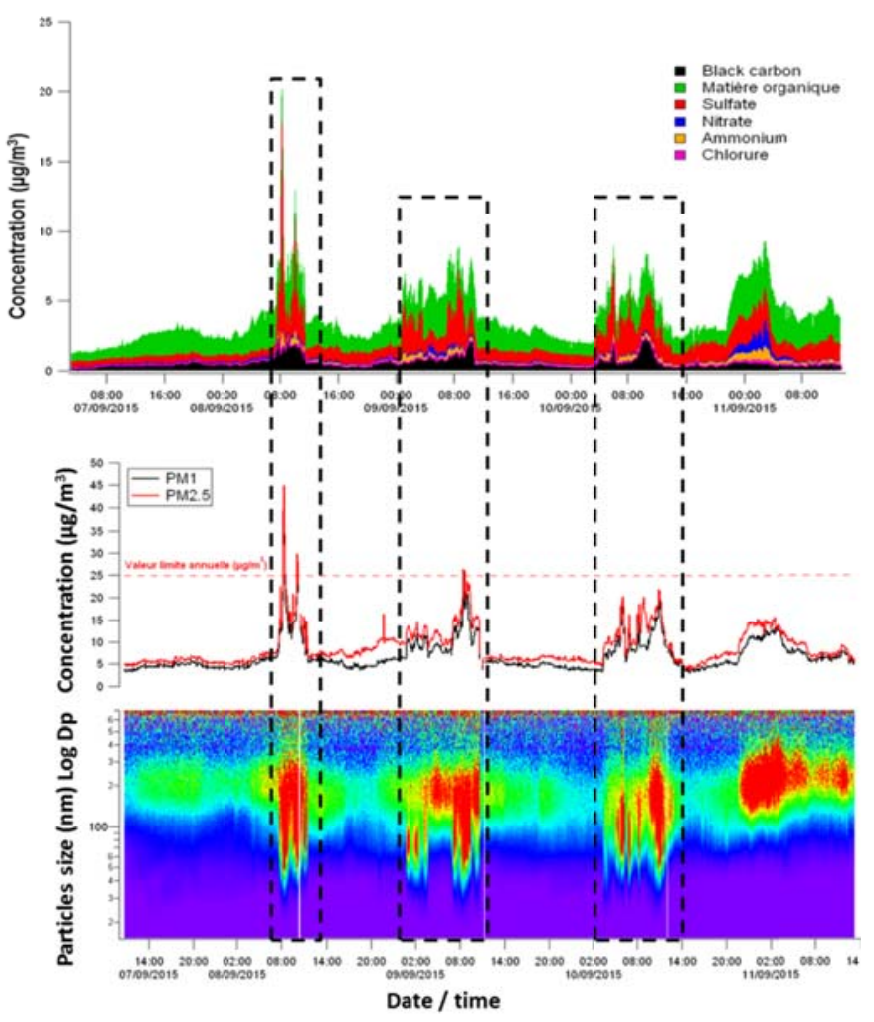

Figure 11: Time series of of PM1 and PM2.5 mass concentrations, submicrometer size distribution and chemical composition 3 different North wind events are represented by dashed lines

The $8^{\text {th }}$ of September emission measurements at boiler CH11 stack exit were performed: several PM sample collections from the main stack were analyzed based on the normative European protocol for filterable PM and condensable PM (EPA Method 202), with complete chemical analysis of the different PM fractions. These measurements lead to a flow rate of $0.5 \mathrm{~g} / \mathrm{s}$ for filterable aerosols and $1.25 \mathrm{~g} / \mathrm{s}$ for filterable plus condensable aerosols. This result is coherent with an emission factor of $0.9 \mathrm{~g} / \mathrm{s}$ for the $\mathrm{CH} 11$ boiler provided by the refinery. From chemical analysis, black carbon versus sulfate ratio is estimated to be of about 5 to $10 \%$. These measurements are 
consistent with MPP measurements and are used as input for PinG model computations.

\subsection{AOT Map Estimation from Hyperspectral data}

Assuming that the plume is dominated by fine aerosol (50 nm mode) composed of $90 \%$ sulfates and $10 \%$ carbon soot (black carbon) and using the linear model for aerosol signatures described in section 3 , we can estimate the total corresponding AOT pixel by pixel in the scene.. A first result is shown in Figure 12 corresponding to $1.5 \mathrm{~m} / \mathrm{s}$ wind speed from the North. In the top of the figure, the boiler $\mathrm{CH} 11$ is seen in the center of the image. In this case, maximum of AOT is close to 0.5 and the mean value around 0.15 . The AOT detection limit is around 0.05 (standard deviation of the AOT map).

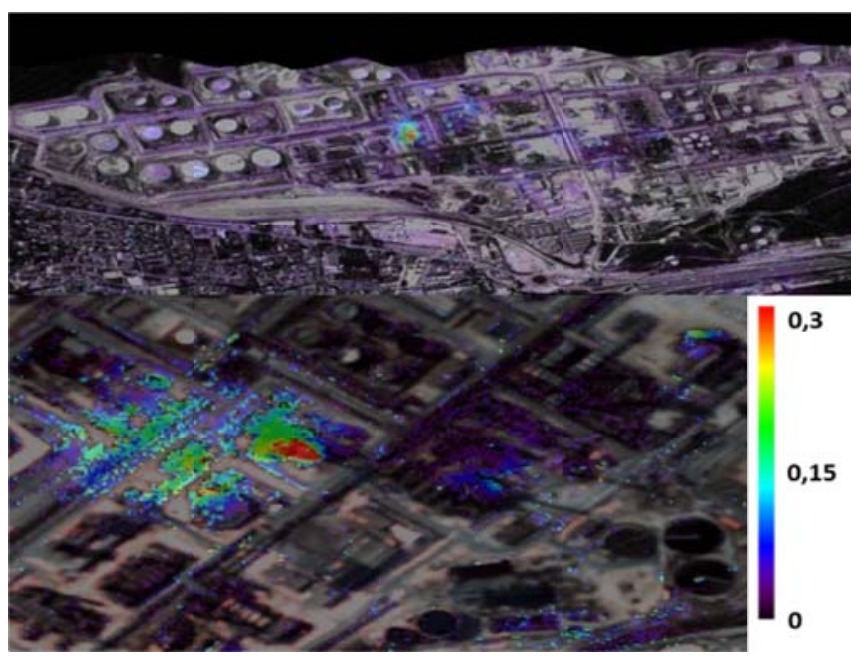

Figure 12: AOT estimation at 550nm sur imposed on the $550 \mathrm{~nm}$ hyperspectral image band. Top for the all refinery, bottom: Zoom on the main source.

We observe that some high AOT values are not linked with the plume in particular in areas where signature should not be analyzed in term of aerosol (shadow and non lambertian material in particular). A threshold on the AOT (typically 1.0 ) is used to reject very high values of AOT.

In a second step, we use a growing detection algorithm. It estimates a first detection threshold (3x the standard deviation seen in the image) to isolate pixels with the highest AOT value. Then looking in the neighborhood of theses firstly detected pixels we confirm or not if the pixel may be in a plume. If this condition is fulfilled we spread the detection map (using a 5x5 kernel) up to another threshold (1x standard deviation of AOT seen in the image). Finally a 3 by 3 Gaussian kernel is used to smooth images and spread the plume. Examples of detection result are shown in Figure 14 and Figure 16. The plume is associated to a spatial cluster and a quantitative analysis is computed.

\subsection{Quantitative Estimation}

Here we discuss about two different events of wind change from $10 \mathrm{am}$ to $12 \mathrm{am}$ the 8 th of September. From differential images AOT are computed and transformed in mass using aerosol density and pixel ground size (2meters in this case). Flow rate is then estimated by calculation of the total mass corresponding to a one meter slice of the plume at different distances from the source using wind speed measurement from the meteorological station available during the TEMMAS campaign. Figure 13 shows the differential in mass (g) at 10am with a "positive" and a "negative" plume before the detection process detailed in section 4.2. Figure 14 and Figure 15 correspond respectively to the detected "positive" plume and mass flow rate estimation at different distance from the source. Flow rate estimated from hyperspectral data near the source increases up to $1 \mathrm{~g} / \mathrm{s}$ at $45 \mathrm{~m}$ and then decreases. This decrease is due to the fact that hyperspectral measurement are not sensitive to lower concentrations, we lose a large part of the plume. Same results are presented Figure 16 and Figure 17 for the "negative" plume corresponding to the $12 \mathrm{am}$ wind change. The mean maximum flow rate is $1.3 \mathrm{~g} / \mathrm{s}$ corresponding to a distance of about $30 \mathrm{~m}$ from the stack, and then decreases up to $100 \mathrm{~m}$. These results are coherent with flow rate provided from stack measurement $(0.5 \mathrm{~g} / \mathrm{s}$ using only filterable aerosols and $1.25 \mathrm{~g} / \mathrm{s}$ using filterable and condensable aerosols). 


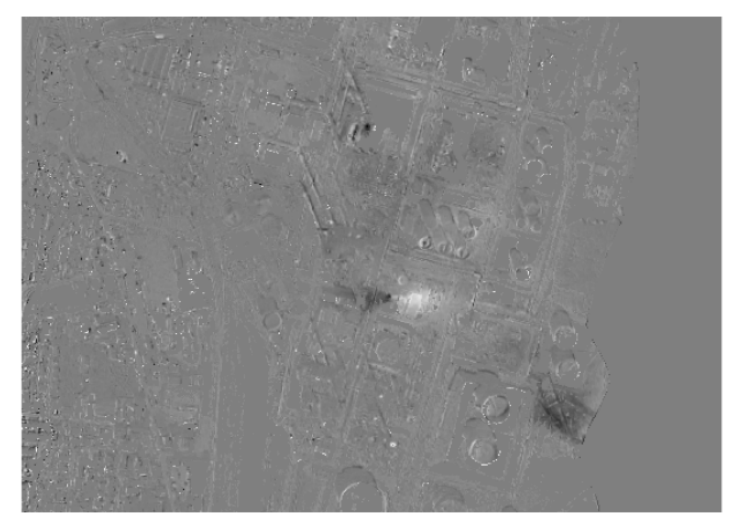

Figure 13 : Extract of the 10am differential image (first change of wind direction in the morning) in mass (g) above CH11 boiler (scale range [-0.05: 0.05]).

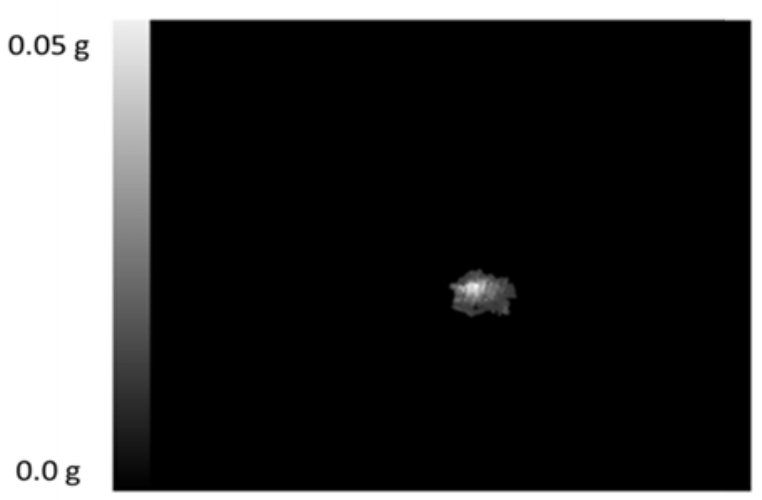

Figure 14: PM detection map of the "positive" plume at 10am (local time) expressed in mass ( $g$ ) from hyperspectral data.

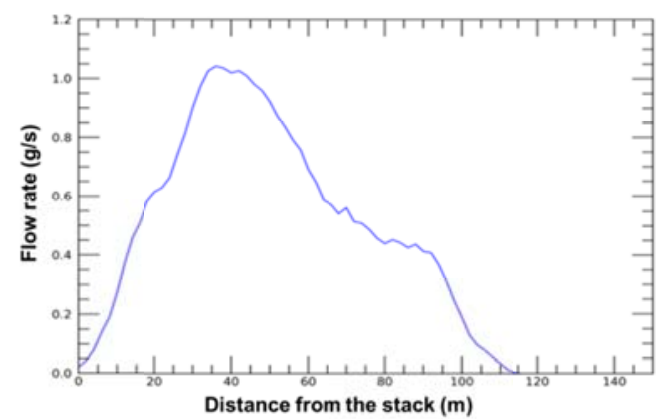

Figure 15 : Flow rate estimation of PM $(\mathrm{g} / \mathrm{s})$ from hyperspectral data using $1 \mathrm{~m}$ slice at different distance from the source $(\mathrm{m})$ for the "positive plume" at 10am the 8th of September. Wind speed is estimated at $1 \mathrm{~m} / \mathrm{s}$.

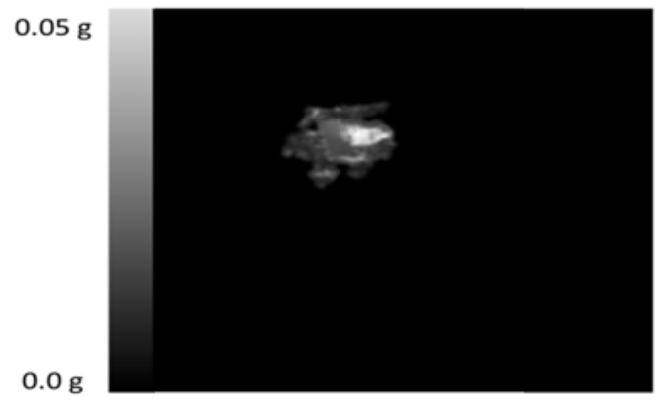

Figure 16 : PM detection map of the "negative" plume at 12am (local time) expressed in mass ( $g$ ) from hyperspectral data.

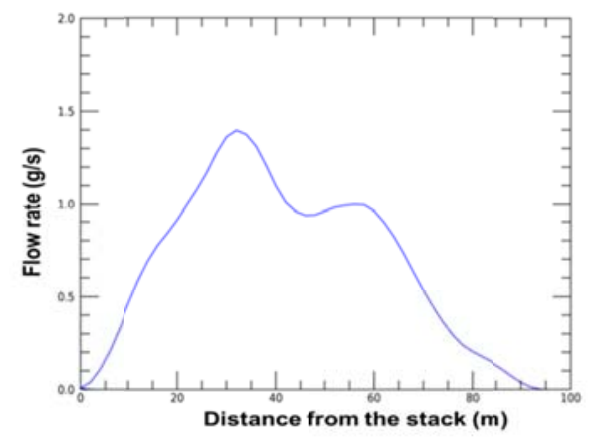

Figure 17 : Flow rate estimation ( $\mathrm{g} / \mathrm{s})$ of PM from hyperspectral data using $1 \mathrm{~m}$ slice at different distance from the source for the "negative plume" at 12am the 8th of September. Wind speed is assumed to be $1.5 \mathrm{~m} / \mathrm{s}$.

Then, the Safety Lagrangian Atmospheric Model (SLAM)[19] and Polyphemus Plume-in-Grid (PinG) were used. PinG model represents background pollutant concentrations in an Eulerian approach, and the refinery is represented with a Gaussian Puff model. SLAM is a Larangian non-reactive dispersion model using pre calculated CFD winds fields. The fine resolution (meter) allows reproducing complex flows in industrial installation.

Given the short distance at which the onboard camera can follow the plumes (less than 100 meters), local modeling is better fitted to represent the location and the physical extension of the plumes at this range than the PinG representation. The dispersion of the primary particles with SLAM allows to refine the estimation of the emission flux from airborne hyperspectral measurements, by extrapolating the hyperspectral data using the SLAM spatial dispersion, as 
hyperspectral measurement are less sensitive to low concentrations (decreases of flow rate estimation). With this approach, both the wind speed at the location of the observed plumes and the fraction of the plume observed by the camera can be corrected. For boiler CH11, the SLAM correction of the raw emission rates estimated with the camera leads to a coherent PM evolution. These emission rates are comparable to the PinG simulation results that consider the physics and chemistry of atmospheric aerosols. Figure 18 shows comparison between estimated flow rate at the stack from measurement $(0.5 \mathrm{~g} / \mathrm{s}$ using only filterable aerosols and $1.25 \mathrm{~g} / \mathrm{s}$ using filterable and condensable aerosols), the PinG simulation results (blue line), hyperspectral estimations (crosses), and hyperspectral corrected using SLAM (circles). These results show a good agreement between the three flow rate estimation methods.

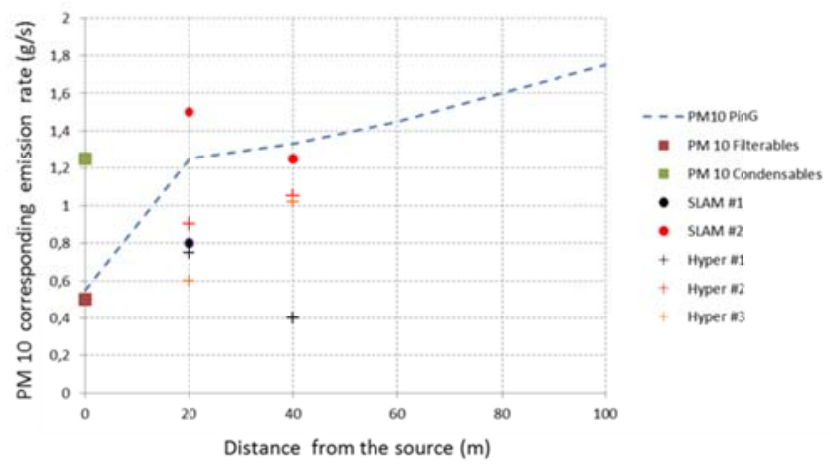

Figure 18: Evolution of the boiler CH11 particles flow rate as a function of the distance from the source. Polyphemus-PinG simulation and flow rate estimated from hyperspectral data (crosses) and corrected using spatial spread modeled by SLAM (circles).

\section{CONCLUSION}

A multi temporal approach from hyperspectral data to detect and analyses optically thin aerosol plumes is described in this paper. This methodology characterizes aerosols in terms of type and size, AOT, mass and flow rate estimation. The retrieved maps have a metric spatial resolution. This methodology was applied to a refinery plume (unseen from a single acquisition) corresponding to a very thin aerosol plumes (AOT estimated in the 0.05 - 0.5 range) over heterogeneous ground. It yields a black carbon to sulfate ratio of 10/90 in mass inside the plume, with an average size distribution smaller than $100 \mathrm{~nm}$ and provides a mean flow rate estimation close to $1 \mathrm{~g} / \mathrm{s}$. These results are in very good agreement with online in situ measurement performed on the ground and samples collected at stack level. The retrieved aerosols concentrations spatial evolution near the source is in good agreement with modelling applied to the refinery main exhaust stack.

Using Hyperspectral data concentration map near the sources could be a great benefit for modelling at regional scale when emissions rates are not well known in term of intensity or location. We assume then that this method can be applied to future hyperspectral satellite measurements with metric or decametric spatial resolution.

\section{AKNOWLEDGEMENTS}

Project supported by the French Agency for the Environment and Energy Management (ADEME), in the context of CORTEA (COnnaissance, Réduction à la source et Traitement des Emissions dans l'Air) funding. The authors gratefully acknowledge the MASSALYA instrumental platform (Aix Marseille Université, https://ce.univ-amu.fr/fr/massalya) for the provision of analysis and measurements used in this publication.

\section{REFERENCES}

[1] A. Alakian., R. Marion, and X. Briottet "Remote Sensing of Aerosol Plumes: A Semi-Analytical Model," Applied Optics Vol. 47, No. 11, pp. 1851-1866, 2008.

[2] A. Alakian, R. Marion, and X. Briottet. "Retrieval of Microphysical and Optical Properties in Aerosol Plumes with Hyperspectral Imagery: L-APOM Method.” Remote Sensing of Environment, Vol. 113, pp. 781-793, 2009.

[3] S. Bojinski, D. Schläpfer, M. E. Schaepman, and J. Keller. "Aerosol mapping over rugged heterogeneous terrain with imaging spectrometer data". Imaging Spectrometry VIII, Proceedings of the SPIE, vol. 4816, pp. $108-119,2002$.

[4] CAFE, Clean Air For Europe, Archive available at : http://ec.europa.eu/environment/archives/cafe/general/keydoc s.html

[5] A. Deschamps, R. Marion, P.-Y. Foucher, and X. Briottet "Estimation of aerosol type from airborne hyperspectral data: A new technique designed for industrial plume characterization". Remote Sensing of Clouds and the Atmosphere XVII; and Lidar Technologies, Techniques, and Measurements for Atmospheric Remote Sensing VIII, Proc. SPIE Vol. 8354, 2012.

[6] A. Deschamps, R. Marion, X. Briottet, and P.-Y. Foucher. "Simultaneous Retrieval of $\mathrm{CO} 2$ and Aerosols in a Plume from Hyperspectral Imagery: Application to the 
Characterization of Forest Fire Smoke Using AVIRIS Data.”, International Journal of Remote Sensing, Vol. 34, No. 19, pp. 6837-6864, 2013.

[7] P-Y. Foucher, A. Armengaud, G. Courtier, P. Déliot, O. Duclaux, A. Durand, M. Fraces, T. Huet, C. Juery, S. Lapeyrie, C. Legorgeu, J-F. Léon, F. Marty, D. Piga, V. Raffort, Y. Roustan, C. Sarrat, B. Temime-Roussel , H. Wortham, "Overview of TEMMAS project", International Conference on Aerosols cycles, Lille, France, 2017

[8] O. Hagolle , M. Huc, D.V. Pascual and Gerard Dedieu,"A Multi-Temporal and Multi-Spectral Method to Estimate Aerosol Optical Thickness over Land, for the Atmospheric Correction of FormoSat-2, LandSat, VEN $\mu$ S and Sentinel-2 Images", Remote Sens., Vol. 7, No. 3, pp. 2668-2691, 2015.

[9] N.C. Hsu, R. Gautam, A. M. Sayer, C. Bettenhausen, C. Li, M. J. Jeong, S.-C. Tsay, and B. N. Holben, "Global and Regional Trends of Aerosol Optical Depth over Land and Ocean Using SeaWiFS Measurements from 1997 to 2010.” Atmospheric Chemistry and Physics Vol.12, pp. 8037- 8053, 2012.

[10] M. J. Jeong., Z. Li, D. A. Chu, and S.-C. Tsay,. "InterComparison and Synergy between the Two Long-Term Global Aerosol Products Derived from AVHRR and TOMS". Thirteenth ARM Science Team Meeting Proceedings, Broomfield, CO. March 31-April 4, 2003.

[11] Y.J., Kaufman, D. Tanré, and O. Boucher,. "A Satellite View of Aerosols in the Climate System." Nature, Vol. 419, pp. 215-223, 2002.

[12] Y. Kim, C. Seigneur and O. Duclaux, "Development of a plume-in-grid model for industrial point and volume sources : application to power plant and refinery sources in the Paris region." Geosci. Model Dev., Vol. 7, pp. 569-585, 2014.

[13] M. King, Y. J. Kaufman, D. Tanré, and T. Nakajima, "Remote Sensing of Tropospheric Aerosols from Space: Past, Present and Future.” Bulletin of the American Meteorological Society Vol. 80, No. 11, pp. 2229-2259, 1999.

[14] G. Le Besnerais and F. Champagnat, "Dense optical flow by iterative local window registration", IEEE International Conference on Image Processing, vol. I, pp. 137-140, 2005.

[15] C. Miesch, L. Poutier, V. Achard, X. Briottet, X. Lenot, and Y. Boucher,. "Direct and Inverse Radiative Transfer Solutions for Visible and Near-Infrared Hyperspectral Imagery". IEEE Transactions on Geoscience and Remote Sensing, Vol. 43, No. 7, pp. 1552 - 1562, 2005.

[16] Y. Philippet,, P.-Y. Foucher, R. Marion and X. Briottet.. "Anthropogenic aerosol emissions mapping and characterization by imaging spectroscopy - Application to a metallurgical industry and a petrochemical complex" , International Journal of Remote Sensing, DOI: 10.1080/01431161.2018.1513665, 2018.
[17] V. Raffort, Y. Kim, L. Donnat, C. Juery, C. Seigneur, O. Duclaux, "Plume-in-grid model for the evaluation of particulate matter contribution of industrial point and volume sources : application to refinery sources in the Paris region", Int. J. Environment and Pollution, Vol. 57, pp. 238 :248, 2015.

[18] D. Schläpfer, M.E.. Schaepman, and K.I. Itten, "PARGE: Parametric Geocoding Based on GCP-Calibrated Auxiliary", Data. SPIE Int. Symp. on Opt. Sc, Eng. and Instr., San Diego (CA), pp 334-344, 1998.

[19]F. Vendel, L. Soulhac, P. Méjean, L. Donnat, O. Duclaux, "Validation of the Safety Lagrangian Atmospheric Model (SLAM) against a wind tunnel experiment over an industrial complex area", 14th conference on Harmonisation within atmospheric dispersion modelling for regulatory purposes, 2011.

[20] H.L. DeWitt, S. Hellebust, B. Temime-Roussel, S. Ravier , L. Polo, V. Jacob, C. Buisson, A. Charron, M. André, A. Pasquier, J.L. Besombes, J.L. Jaffrezo, H. Wortham and N. Marchand. Near-Highway aerosol and gas-phase measurements in a High Diesel Environment. Atmos. Chem. Phys., 15, 4373-4387, 2015. 